Article

\title{
Using Community-Based Social Marketing Techniques to Enhance Environmental Regulation
}

\author{
Amanda L. Kennedy \\ Australian Centre for Agriculture and Law, University of New England, Armidale, New South Wales \\ 2350, Australia; E-Mail: amanda.kennedy@une.edu.au; Tel.: +61-2-6773-3493;
}

Fax: +61-2-6773-3602.

Received: 2 April 2010 / Accepted: 21 April 2010 / Published: 26 April 2010

\begin{abstract}
This article explores how environmental regulation may be improved through the use of community-based social marketing techniques. While regulation is an important tool of sustainability policy, it works upon a limited range of behavioural 'triggers'. It focuses upon fear of penalty or desires for compliance, but individual behaviour is also affected by beliefs and values, and by perceived opportunities for greater satisfaction. It is argued that more effective environmental laws may be achieved using strategies that integrate regulation with community-based social marketing. Case studies where community-based social marketing techniques have been successfully used are examined, and methods for employing community-based social marketing tools to support environmental regulation are proposed.
\end{abstract}

Keywords: community-based social marketing; environmental regulation

\section{Introduction}

There is evidence that the existing environmental regulatory framework is unlikely to achieve the sustainable outcomes desired within society. Individual compliance with regulation is motivated by a variety of factors, only some of which are targeted by regulation. Behaviorally effective law seems more likely through a combination of regulatory and non-regulatory approaches to simultaneously address multiple drivers of behavior, some of which are likely to respond to marketing stimuli. This paper makes a case for refocusing environmental regulation upon the behavior of individuals, and 
combining traditional legal instruments with behavior change tools, to better guide citizens to change their patterns of behavior with respect to the environment.

Insights from the field of social marketing, and in particular, the specific tools of community-based social marketing, can assist in reinforcing regulatory strategies. Community-based social marketing aims to produce behavioral change via direct communication and community level initiatives, concentrating upon removing barriers to change. Community-based social marketing tools are well documented; however, the use of integrated community-based social marketing programs to support regulation has not been as widely explored. The available case studies indicate that compliance with regulation may be greatly increased by applying community-based social marketing approaches. This challenges regulators to think strategically about the use of supplementary tools to enhance regulatory compliance.

There are also implications for sustainability. Mechanisms that can support regulation to change individual behavior are important because of the environmental effects of individual behavior. In the United States alone, approximately one-third of the nation's greenhouse gas emissions (almost $8 \%$ of international greenhouse gas emissions) are generated by individuals in a private, non-industrial capacity [1]. At a time when international targets for pollution reduction are also being hotly debated, means for more effective behavior change methods are needed.

This paper begins by exploring the nature of environmental regulation, recapitulating the behavioral underpinnings of regulation of individual behavior. It then moves on to explore the suite of tools advocated by the community-based social marketing movement which may complement regulation. Literature exploring the use of complementary behavioral techniques alongside regulation is discussed, followed by case studies where community-based social marketing programs have been applied to enhance the effectiveness of regulation. The paper concludes with a discussion of methods to employ community-based social marketing techniques to enhance environmental regulation.

\section{Behavior and Environmental Regulation}

Regulation has been used to alter behavior with respect to the environment, with varying degrees of success [2-4]. Statistics showing environmental degradation suggest that regulation is failing to achieve sufficient outcomes in many instances. Individuals, collectively, make a significant contribution to environmental degradation, but it is particularly difficult to effectively regulate individual environmental behaviour. It is argued here that regulation needs to be complemented with approaches that engage of all the motivating factors that drive individual compliance. This section of the paper examines the motivating factors of individual compliance which ought to be given consideration when seeking to alter individual behavior.

\subsection{The Behavioral Underpinnings of Regulation}

Compliance with regulation is informed by a range of factors [5]. The literature focuses predominantly upon the deterrent aspects of compliance - that is, motivation to comply through fear of penalty or punishment for non-compliance [5,6]. This is based on Becker's influential deterrence model (following Jeremy Bentham, [7]), which holds that obedience to regulation is encouraged by a threat of punishment, outweighing the utility of engaging in illegitimate activity) [8]. Becker's model 
is based on a rationalist view that the decision to engage in a criminal enterprise depends upon the likely utility of committing the crime, and the probability and severity of sanctions. In a similar vein, Tyler's instrumental perspective holds that individuals are motivated by self interest and that their behavior is shaped through changes in tangible incentives and penalties [9]. Compliance, therefore, may be encouraged by increasing the threat so that it outweighs any perceived benefits of transgressive behaviour. However, as Sutinen and Kuperan note, this model has shortcomings. It does not account for situations where low penalties have resulted in high compliance, and fails to consider the possibility that higher penalties and greater enforcement may not be cost effective or feasible [10]. The deterrent model of compliance fails to account for other factors which appear to motivate compliance. As Sutinen and Kuperan note, regulatory design that fails to account for such factors as personal morals may be ill-founded [10].

May categorizes the deterrent basis for compliance as a 'negative' motivation, and notes that there can also be alternative 'affirmative' motivations for compliance which 'emanate from good intentions and a sense of obligation to comply' ([5], p. 61). Often, such positive motivators are not fully understood [5]. As a result these beliefs and values may be overlooked as fundamental when designing a regulatory strategy [2]. Tyler proposes an alternative to the instrumental perspective mentioned earlier to explain these additional motivations for compliance - the normative perspective. This links compliance to reasons intrinsic to the individual—such as their personal moral views, and whether the law is perceived to be fair and legitimate [9].

Sutinen and Kuperan refer to intrinsic motivation and morality in the desire to "do the right thing" as a factor that motivates compliance [10]. As they note, there is ample evidence that morality is a common motivating factor: “...many people persist in investing substantial proportions of their resources into public goods despite conditions designed to maximize free riding. In experiments of repeated prisoner dilemma games, over half of the subjects cooperate without being coerced or paid. Several experiments have shown that many people return lost wallets to their owners with all of the money inside. We also witness anonymous contributions to charity-above and beyond what tax incentives can explain. It is customary for people to leave tips in restaurants in distant cities which they never expect to visit again..." ([10], p. 178), see also [11-15]. May emphasizes that regulatees bring to the table attitudes and beliefs about regulations which impact upon their response to regulation [5]. Trust and legitimacy are noted as affirmative motivations for compliance. May states that where there is confidence in the regulatory authority and belief that the regulations are reasonable and just, 'quasi-voluntary' compliance with regulation is fostered [5,9]; see also [16,17]. Further, May argues that the desire of regulatees to gain the respect of others and a concern for their reputation can also contribute to affirmative motivations for compliance [5]; see also [10,11].

It is clear that compliance with regulation may also arise from 'a sense of obligation and shared commitments for fulfilling an implicit regulatory social contract' ([5], p. 61), rather than deterrent fears alone. While deterrence and enforcement have a vital part to play in regulatory systems, affirmative motivations, shaped by the attitudes, beliefs and knowledge of regulatees, may enhance the behavioral effectiveness of regulation.

There has been an increased emphasis in the literature upon incorporating voluntary and quasi-voluntary mechanisms which draw upon affirmative motivators to improve the behavioral effectiveness of regulation [5], see also [2,18-24]. The literature refers to concepts such as 'smart' [18] 
and 'responsive' [20] regulation, involving a mix of regulatory and non-regulatory instruments. 'Self-regulatory' mechanisms for sustainability have permeated corporate behavior, with an abundance of literature on corporations moving 'beyond compliance' using environmental management practices, such as corporate social responsibility, triple bottom line reporting, and corporate citizenship initiatives such as the UN Global Compact and the EU's Eco-Management Audit Scheme (EMAS) [25-43]. With the ISO 26000 guidelines (non-certifiable) on social responsibility for organizations to be released in 2010, voluntary mechanisms have gained credibility as a means to encourage sustainable corporate behavior beyond compliance. However, it is not the aim of this paper to revisit the extensive literature on corporate behavior. The focus of this paper is upon providing a framework to encourage sustainable behavior at what is arguably the 'next frontier': the behavior of the individual [44].

\subsection{Regulation of Individual Environmental Behavior}

Individual behavior is the cause of a significant number of environmental problems, yet control of individual behavior has been largely absent from environmental legislation, which generally targets industrial sources of environmental harm [1,45-48]. In the United States alone, Vandenbergh and Steinemann [45] found that individuals account for 32\% of the United States' annual greenhouse gas emissions, totaling approximately $8 \%$ of global greenhouse gas emissions. This is larger than emissions totals from Africa, Central America and South America combined; and greater than emissions from every other foreign country apart from China [45]. Vandenbergh [49] also reports that individuals are the largest source of dioxin emissions in the United States, and that individuals collectively produce more air toxins than all large industrial sources in the country. Individuals are also responsible for the emission of more than $30 \%$ of ozone precursors in the United States (through the use of vehicles, residential energy consumption and use of various consumer products) [46], as well as contributing to indoor air pollution, water pollution and waste contamination problems [47]. As Johnson ([47], p. 120) states, “...many of the most vexing environmental problems that remain cannot be resolved without limiting individuals' environmentally destructive choices or at least without spurring individuals to take actions that reduce the harm that they cause to the environment." As Vandenbergh and Steinemann argue, small shifts in individual behavior will result in emission reductions that will exceed the total emissions of whole industries, as well as other countries and even continents [45].

Legislation can directly address some of the problems caused by what Stern labels "personal, private-sphere, environmentally significant behaviour" ([50], pp. 10,786), by the restriction or encouragement of certain behaviours [1]. However, as noted in the previous section, 'command and control' legislation relies upon only some of the drivers of behavior [47]. There are also non-legal challenges in the implementation of law. These include the need to ensure that citizens know their obligations and have the means to comply. It is also expensive to design and enforce regulatory programs against individuals when compared to industry groups and corporations [46,47]. As Vandenbergh and Steinemann state, '...individuals often lack adequate information, suffer from cognitive biases, are subject to social influences, and act in ways that are not easily understood through the lens of a rational-actor model' ([45], p. 1739). Additionally, regulating individuals may prove politically unpopular [51]. As Johnson notes, there is more "pollution reduction bang for the buck" 
to be gained by focusing on industry, as well as a reduced possibility of public resistance to regulation ([47], p. 124). However, the contribution of individuals to environmental degradation is sufficiently important to justify better regulation.

The literature has recognized that there is a need for legislation to focus on individual behavior to improve sustainability outcomes. It provides some guidance as to effective environmental regulatory design to engage individuals $[1,45,46,52]$, including the provision of pollution reduction targets and incentives for individuals. In addition to refocusing regulation upon the individual, it is necessary to ensure that such regulation is effective. There is a growing recognition that mechanisms which harness the intrinsic motivations of individuals can improve compliance, including the use of norms and other behavioral tools [46,50-55], and removal of barriers to sustainable activities [56]. Complementary methods have achieved desired behavioral outcomes in several case studies; however, greater success may be accomplished when a combination of interventions is used at the community level. The community-based social marketing movement advocates a tightly structured program involving removal of barriers to change, attacking multiple drivers of environmental behavior through the use of behavior change tools, and doing so at the community level using direct personal contact [57]. While such approaches will not be universally applicable, there will be many instances where these methods could effectively support the implementation of regulation.

The remainder of this paper demonstrates ways in which research of community-based social marketing programs applied to strengthen efforts to change behavior offers a new direction for regulatory research and praxis. While only a small number of studies have explored the specific issue of how comprehensive community-based social marketing programs may improve the effectiveness of regulation, they nevertheless illustrate that regulatory approaches, when supported by education and a combination of community based outreach mechanisms, may be more effective than those which are not supported by such techniques.

\section{Community—Based Social Marketing}

Community-based social marketing developed from social marketing, which has not always been able to transcend the barrier between raising awareness and actual behavior change, particularly when it comes to complex issues. Community-based social marketing has proven to be an effective method of affecting actual attitudinal and behavioral change by taking an interactive approach to information delivery, employing behavioral changes tools drawn from social science research. With a focus on overcoming barriers to change [57], community-based social marketing mechanisms provide a well specified complement to regulation. This section of the paper explores the development of community-based social marketing from social marketing. This is followed by a description of the elements of community-based social marketing, with a particular focus on the behavior change tools drawn from social science research. Case studies are revised which illustrate the potential for community-based social marketing methods to be used as part of a regulatory strategy.

\subsection{Social Marketing and the Development of Community-Based Social Marketing}

Social marketing is the application of traditional marketing techniques to inform the public about issues. It aims to achieve socially desirable behavioral change, such as safer driving or healthier 
lifestyles [58-62], and is often used by nonprofit and other organizations that focus on those issues. Andreasen [61] asserts that a social marketing program must have the goal of influencing voluntary behaviour to benefit individuals or society, rather than marketing the organization itself. Information-based advertising is generally used in social marketing campaigns to increase awareness of a social issue, and to 'sell' an attitudinal or behavioral change. Proponents argue that social marketing must be more than the mere promotion of a particular idea [63,64], and that it must be supported by robust market research which identifies the target audience and its behavioral patterns $[61,65]$.

Despite social marketing's growth as a discipline, and an increase in academic and governmental support, it is limited by a range of challenges, including confusion over its position and role [66], and the potential for incorrect application [61]. A common criticism of social marketing is that extensive consumer and market research is not undertaken in advance of implementation, creating a gap between the rhetoric and reality of social marketing practice. As Kline Weinrich notes, “...like all buzzwords, the term is often misused", and "...too often, the well-intentioned nonprofit director who uses marketing techniques to raise funds for the director's organization or the health educator who creates a television commercial without even talking to the people the educator is trying to reach believes that he or she is practicing social marketing" ([67], p. 3).

Pfeiffer's analysis of a social marketing program in Mozambique illustrates how social marketing techniques may be misapplied [68]. This social marketing project promoted the use of condoms. However, stakeholders felt that the project promoted promiscuity, and contributed to the burgeoning AIDS crisis. Pfeiffer notes that Western NGOs offered '.... prepackaged approach to AIDS prevention... that emphasized "cost-effectiveness" as the bottom line for priority setting in health' ([68], p. 78). This detracted from the project's ability to foster good community relations, and ultimately, trust in the project. Pfeiffer notes that social marketing approaches to "changing behaviours as complex and socially volatile as sexuality may not only be ineffective, but may actually be harmful, because genuine community participation, dialogue, and monitoring are excluded from the process, while structural determinants and social context of "high-risk" behaviors are left unaddressed" ([68], p. 79).

A further critique of social marketing is its reliance upon advertising. Commentators have suggested that advertising is insufficient to motivate the degree of behavioral change that is often needed [57,62]. While it is easy to distribute print media and radio/television advertisements, this is expensive and frequently ineffective at changing human behavior [57,69-70]. McKenzie-Mohr and Smith note (drawing upon the earlier research of Costanzo et al.) that the difficulty of changing behavior is often underestimated [57,70]. Passive mass media marketing techniques are often powerless. Mere awareness of a problem (such as environmental degradation), and the economic self-interest gains from behavior change, may be insufficient to prompt meaningful behavioral changes [71]. Johnston argues that information based advertising undermines what it seeks to accomplish - the encouragement of individuals to take an active role in altering their behavior [71]. A diverse range of barriers to adoption of the desired behaviors may exist, which an information based educative campaign alone will do little to overcome [57,71].

Community-based social marketing takes a more grounded approach by identifying barriers to change, then applying behavior change tools to address these and to foster the desired behavioral 
change. Community-based social marketing promotes the strategic use of community-based direct initiatives, rather than mass media advertising alone [57]. The development of community-based social marketing was born out of a desire to improve the effectiveness of environmental campaigns which relied heavily upon information-based advertising [57,72]. Kollmuss and Agyeman note that community-based social marketing has been successful because it can transcend "the gap between knowledge [and] action that has characterized many local environmental and sustainability projects to date" ([72], p. 240).

\subsection{The Elements of Community-Based Social Marketing}

Community-based social marketing has its foundations in social psychology. It is based on the premise that behavior change initiatives are most effective when they are delivered at the community level using personal contact [57]. It focuses upon removing barriers to behavioral change while concurrently promoting the benefits of change [57]. It does this through the use of behavior change tools drawn from social science research, including seeking commitments from participants; offering prompts as mental cues to encourage change and its benefits; developing and reinforcing norms; using captivating, credible and effective communication strategies; and using incentives that support the behavior change sought [57]. Proponents of the community-based social marketing movement encourage pilot studies of the intended program in a small section of the relevant community, and ongoing evaluation of a community-based social marketing program to measure the behavior change achieved and to refine the strategy if necessary [57]. As a result, community-based social marketing methods are clearly specified, and there is a body of empirical case studies to guide its application and inform research results. Standard social and consumer marketing approaches suggest many methods that are similar but less well documented and specific.

As the community-based social marketing movement has grown, reports of successful community-based social marketing initiatives have emerged, in particular, showing how specific tools may be implemented to foster behavior change. The following discussion is of specific techniques designated in the community-based social marketing literature. It is important to reiterate that because behavior is complex, contextual and multi-faceted, there is no mechanistic substitute for sophisticated analysis of the behavioral system targeted for change, or the people who comprise that system [23].

A process of staged building of 'commitment' has been used with often surprising results (see McKenzie-Mohr and Smith [57] for a useful summary). Seeking commitment to an initially small request can build commitments to larger requests [57] because individuals like to be perceived as behaving consistently [57,73]. An individual who agrees to an initial request views himself or herself as a supporter of a particular cause, and does not want to be perceived as inconsistent.

Public commitments are particularly significant. Pallak, Cook and Sullivan's [74] report of the use of public commitment to reduce energy consumption in Iowa City provides a good example (see also [75,76]). Household use of natural gas and electricity was assessed during short home visits. Information about reducing energy consumption and conservation strategies was provided, and a public commitment to the program sought (residents were told that their names would be publicized with the results of the program). A second group were provided with home visits but were only asked to make a private commitment. A third control group were not provided with the home visits nor asked 
to make any commitment. In the group from which a public commitment was sought, a decrease of approximately 10-20\% of energy usage was reported. No significant decrease in consumption was reported in the control group or the group making a private commitment [74].

Communication as a tool of community-based social marketing builds upon marketing theory, which holds that attention must be captured to initiate behavior change [57]. Communication must therefore be vivid and personal, targeted, easy to remember, and presented by a credible source [57]. Modeling the preferred behavior is one effective method to encourage behavior change, regardless of the method of communication [57,77,78]. Another method, coupling effective communication and commitment, is illustrated by a program implemented by the Pacific Gas and Electric Company in California [79]. Home auditors conducted free home inspections and provided advice on energy efficiency. They employed communication strategies to capture the homeowner's attention - including comparing cracks around doors to a hole the size of a ball, and explaining the costs of not implementing improvements. They also actively involved the homeowner in the audit. The success rate of the program was high, with an estimated $60 \%$ of homeowners implementing improvements (see also [80,81]).

Incentives are a useful tool to motivate behavior change [57,82]. Incentives are most effective where the incentive and the behavior are closely paired, and where they are visible [57,82]. Positive incentives have been shown to be more effective than imposed disincentives. McKenzie-Mohr and Smith provide the example of people evading user-fees for garbage collection by illegally dumping in public waste baskets [57]. Wang and Katzev report a paper recycling scheme at a dormitory in Portland, Oregon which successfully incorporated incentives and commitment [83]. In the pilot program, four groups of residents were monitored - one group that signed a public commitment to recycle for four weeks, another group that made a private commitment, a group that was offered incentives to recycle (coupons for local businesses), and a control group that was given information leaflets. The first three groups demonstrated a significant increase in recycling, with the group provided with incentives increasing its recycling by 54\%. The public commitment group increased its recycling practices by $48 \%$ and the individual commitment group by $67 \%$. The control group, which was only provided with information, increased its recycling by $9 \%$ [83].

Prompts can remind people to engage in activities that they might otherwise forget (such as bringing recyclable bags to the supermarket), even though they may not result in attitudinal change on their own [57]. A prompt must be noticeable, self-explanatory, and in close proximity to the site where the targeted behavior is to be carried out [57]. The use of prompts was explored by Austin et al. $[85,86]$ in their analysis of participation in a university campus recycling program. One department had recycling information signs detailing acceptable recyclable materials placed in immediate proximity to recycling and trash receptacles; another had the signs placed above the receptacles which were then placed several meters apart. The proximity of the prompts proved to be a key link; in the first department, recycling activity increased by $54 \%$, whereas in the second department, recycling behavior was initially improved by only $17 \%$, then later increased to $22 \%$ once the receptacles and signs were moved closer together.

Social norms are emphasized in the community-based social marketing toolkit. Vandenbergh and Steinemann note that social norms "... are informal obligations that are enforced through social sanctions or rewards" ([45], p. 1706, see also [53]). Schultz et al. note that the development of social 
norms have been found to "...not only spur but also guide action in direct and meaningful ways" ([87], p. 429). Social norms research has uncovered two constant factors. Most individuals overestimate the prevalence of undesirable behavior, and individuals will assess their own behavior against their perception of the norm [87-90]. This perception of prevalence can produce a 'boomerang effect', whereby individuals who may otherwise abstain from undesirable behavior may engage in it, complying with a perceived common standard of behavior. Campaigns that utilize social norm tools communicate that undesirable behavior is occurring less than believed [87].

Schultz et al. used social norms to encourage a reduction in electricity consumption [87]. In San Marcos, California, 290 households were provided with normative information about energy consumption and their energy use was monitored over four weeks. At the beginning of the monitoring period, all households received door hangers which displayed information about how much energy the household had used in the previous week, normative information about the average energy consumption of houses in the neighborhood, and suggestions for reducing energy consumption (descriptive norms). Half of the participants who used less energy than the neighborhood average received normative support (a smiling face emoticon drawn on their door hangers), and the other half received descriptive norm information. Half of the households who had higher than average energy use had a frowning face emoticon drawn on their door hangers (with the remaining half receiving the descriptive norm information only). The happy and sad face emoticons conveyed approval or disapproval for the level of energy consumption. Those households that received the frowning face emoticon reduced their electricity use by $6 \%$, compared with a reduction of $4.6 \%$ in those households who only received the descriptive norm information. For the households who had lower than average electricity use at the beginning of the campaign, those who received the smiling face increased their energy consumption by $1 \%$, compared to a $10 \%$ increase observed in the group who did not receive this information [87]. Schultz et al. concluded that the additional usage of norm information assisted in encouraging lower-than-average energy consumers to maintain their rate of energy consumption (approval), and assisted in motivating higher-than-average energy consumers to reduce their consumption (disapproval) [87]. As of early 2009, this strategy was being piloted in other metropolitan areas throughout the United States [91].

The use of social norms to achieve collective environmental behavior change has been explored widely in legal scholarship, with optimism that social norms management offers a "cheap and effective alternative to more traditional regulatory means" ([52], p. 1233, see also [92]). However, some commentators have concluded that reliance upon social norms may not prove successful where the problem is characterized as 'large-number, small-payoff' (where change is required by a large number of people who have little economic incentive to do so), or where the desired behavioral change requires significant effort on the part of the individual [52]. Carlson notes that the feasibility of social norms management as an alternative to formal regulation depends upon "...the nature of the social problem, the context in which it arises, and the availability of other regulatory tools" ([52], p. 1233). Scholars have argued that the activation of personal norms may prove more fruitful as a complementary technique to regulation [1,45-47,49,53]. Personal norms have been defined as "...informal obligations that are enforced through an internalized sense of duty to act, as well as guilt or related emotions for a failure to act” ([45], p. 1706). While not described as 'personal norms', 
several tools of community-based social marketing (seeking commitment, use of prompts, personal communication, and use of positive incentives) are arguably geared towards activating personal norms.

In addition to the growing body of academic reports of community-based social marketing, websites such as 'Tools of Change' (http://www.toolsofchange.com) and 'Fostering Sustainable Behavior: Community-Based Social Marketing' (http://www.cbsm.com) provide many other examples of successful community-based social marketing. Environmental psychology literature is also rich with illustrations of behavioral interventions that may be implemented as a part of a community-based social marketing program to encourage environmentally sustainable behavior [93-97].

\section{Using Community-Based Social Marketing Programs to Support Environmental Regulation}

While regulation alone may succeed in changing behavior in some situations, relying solely upon the force of the law may not be optimal regulatory practice [57,98]. McKenzie-Mohr and Smith argue that the ability to regulate effectively is contingent upon the willingness of people to be regulated [57]. The examples discussed in the previous section highlight the potential for behavioral interventions to influence this willingness to be regulated, thus improving compliance [98]. The development of environmental regulation theory and practice, and of community-based social marketing, has occurred largely in parallel. More concerted research and practice could realize the benefits of synergies between them. [1,45-57,99-101]. Such an effort should yield substantial practical and theoretical benefits for environmental law scholarship. The literature shows some use of behavioral interventions as a part of regulatory strategy, and case studies detail the specific use of community-based social marketing programs in conjunction with regulation.

\subsection{Individual Behavioral-Based Interventions as a Part of Regulatory Strategy}

Considerable recent research has shown the use of social norms as a complement, and in some cases an alternative, to regulation [92,101-104]. The literature indicates that when "...the material benefits of cooperation to the individual are large and the behavior occurs in close-knit groups" ([53], p. 1102), social norms may assist in achieving significant behavioral changes. An increased perception of social norm enforcement can flow on to 'norm cascades', which can influence larger sections of society [92]. However, in recent times scholars have argued that social norms function in a narrow set of circumstances, which alone may not be sufficient to induce desired behavior changes [52]. In noting the 'outpouring' of legal scholarship about norms, Carlson explains that much of the law and norms literature focuses upon changing norms in small, homogenous groups. She questions the ability for social norms management to change 'large-number, small payoff collective action problems,' which arguably describes many environmental problems [52]. Vandenbergh suggests that “...in an increasingly crowded society, individuals face numerous situations in which acting in their personal interest will harm the collective interest, but their large numbers undermine the influence of legal and social sanctions" ([53], p. 1102). This has prompted scholars to consider the extent to which individuals can be motivated to change behavior for a reason other than the fear of social sanctions, or the opportunity for private gain [53].

As an alternative to social norms, several scholars have suggested that activation of personal norms may influence individual environmental behavior. Stern argues that if contextual factors are 
robust - where laws are effective, and incentives, penalties and social norms are strong - there will be little room for personal factors to influence behavior [50]. However, where these contextual influences are weak, factors such as personal norms and beliefs are more likely to influence individual behavior. In earlier work, Stern et al. describe the 'value-belief-norm' theory of environmentally significant behavior, which provides a framework for assessing individual behavior [100]. Their theory holds that individual choice is driven by personal norms (an internal obligation to act in a particular manner). Personal norms are activated when an individual believes that violation of a norm would adversely affect something the individual values (termed 'awareness of consequences' (AC) in the literature), and that by engaging in a particular activity the individual would have responsibility for those consequences (termed 'ascription of responsibility' (AR) in the literature) [50,100]. Stern et al. note that where these 'AC' and 'AR' beliefs are changed, it is possible to influence individual behavior. To change beliefs, Stern indicates that narrow educational approaches (such as telling people what behaviors are environmentally beneficial, or simply that environmental disaster is looming) have not proven overly effective [50]. However, programs where information "....arrives at the time and place of decision, is linked to the available choices, is delivered from trusted sources, and is delivered personally" are more likely to yield success [50]. Stern also indicates that personal norm activation may be enhanced in a 'community context', where “...face-to-face communication, mutual interdependence, and the possibility for social influence can build interpersonal norms that buttress personal norms" [([50], p. 10788). This strand of regulatory research is consistent with the community-based social marketing literature outlined earlier.

The activation of personal norms is also a focus in Vandenbergh's research. Drawing upon Ellickson's seminal work, Order Without Law [105], Vandenbergh proposes that personal norm activation is an effective approach to reducing environmentally harmful individual behavior [53]. Vandenbergh argues that information can trigger a personal norm if it can show an individual that his or her behavior causes an environmental problem, and that a reduction in that behavior would lead to a reduction in the problem [53]. If properly communicated, he suggests, the law could provide the information necessary to make individuals aware of the consequences of their actions and accept responsibility for them [53]. He argues that the law can change beliefs about the nature of the problem, and challenge beliefs about any social consensus surrounding the problem. Law is particularly effective in doing so when it requires disclosure of specific information targeted at personal beliefs, which may in turn activate personal norms [53]. Vandenbergh proposes that publication of data on individual toxic release will activate personal norms sufficient to reduce environmentally harmful behavior, absent other barriers to the behavior change [53]. He suggests an Individual Toxic Release Inventory, modeled upon the industrial equivalent, as a potential statutory based mechanism that would convey mean and aggregate data on the relative toxic release of individuals [53]. The use of mean and median data is proposed, as gathering information on any one individual would be too cumbersome. Mean and aggregate data have been shown to be sufficient to invoke personal norms of environmental stewardship [53].

Vandenbergh cautions that even where information triggers a personal norm, it will have little effect if an individual believes that others are not 'doing their fair share' ([53], p. 1124). To ameliorate this, he proposes invoking the personal norm of reciprocity (that individuals will cooperate if they believe others are cooperating) through the provision of information that leads leads an individual to believe 
that others are engaged in the desired behavior [53]. In the case of an Individual Toxic Release Inventory, Vandenbergh suggests that the provision of information regarding relative toxic releases of individuals (in addition to median data) would achieve this. In a similar vein, Vandenbergh and Steinemann propose another information-based regulatory strategy designed to activate personal norms, the Individual Carbon-Release Inventory [45]. They suggest a well-designed and integrated information campaign to inform individuals of the mean, aggregate and relative carbon emissions of individuals, seeking to activate the personal norms of environmental concern and reciprocity [45]. Once more, this regulatory research has strong parallels with the community-based social marketing literature, and the specific techniques that have been empirically demonstrated to have an effect on environmental behavior.

Dernbach provides a comprehensive analysis of how climate change legislation could be refocused to activate personal norms and engage individuals in positive environmental behavior change [1]. He suggests that Congress could require the Environmental Protection Agency (EPA) to set reduction targets relevant to per capita energy consumption to directly influence individual environmental behavior [1]. Dernbach also argues that individual engagement may be encouraged through articulation of legislative findings and statements of purpose [1]. He also notes that the development and publication of reliable information, and effective communication of alternative choices open to individuals, is necessary to activate personal norms and engage individuals in climate change efforts [1]. Dernbach also advocates the consideration of incentives (such as tax credits) in climate change legislation targeted at individuals, as well as allocation of allowances for individuals who engage in energy efficient activities [1]. These are all tools which are enunciated in the community-based social marketing literature explored earlier. A final recommendation is the provision of analysis and monitoring of the behavioral effectiveness of incentives within the legislation, giving way to modification of such efforts where necessary [1]. Once again the parallels with the community-based social marketing praxis are pronounced.

It is difficult to change individual behavior with information alone where barriers exist to less environmentally harmful alternatives, or where it is more convenient to engage in the harmful behavior [1,56]. Pollard advocates the removal of barriers to sustainable transportation and housing choices by individuals, more sustainable alternatives, and the cessation of subsidies for environmentally destructive behavior [56]. Dernbach also suggests that information alone will be insufficient to prompt behavior change [1]. He notes that it may be necessary to increase the benefits of desired behaviors or or remove obstacles to them [1]. This may include the use of financial or other incentives and disincentives. Similarly, Carlson indicates that social norms have been more readily activated by methods that increase the convenience of the desired behavior, such as a single bin for commingled recyclable material, as opposed to separate bins for different kinds of recyclable material [52]. The concept of removing barriers to change (while simultaneously promoting the benefits of change) is central to the community-based social marketing movement, and has been empirically demonstrated.

Johnson highlights an interesting non-regulatory mechanism for activating personal norms - religion [47]. He argues that churches and religious organizations have delivered strong messages about individually-caused environmental harm. These messages have “...activated personal norms of stewardship and social justice that have spurred changes in individual attitudes and behavior 
even without the imposition of command and control or economic-based programs by government" ([47], p. 120). Lin posits that evangelical techniques such as preaching and leadership, personal witnessing, storytelling, affirmation and obtaining personal commitment may help develop or refresh norms of personal environmental responsibility [48]. As Lin notes, former Vice-President Al Gore is 'essentially the world's leading "evangelist"' against global warming, frequently invoking religious imagery and terminology in preaching the climate change message ([48], p. 1181). Appropriate 'cultural vouchers', who have credibility and authority within their cultural group to convey messages that will invoke personal norms, transcend evangelical practice [48]. As in religious evangelism and other contexts, storytelling also may prove a useful communication method, making abstract narratives 'concrete and personal' by highlighting impact upon human beings ([48], p. 1186). The act of 'witnessing', using personal testimony and outreach to provide evidence of one's 'faith', is another evangelical tool suggested by Lin. This roughly correlates with the community-based social marketing tool of direct, personal contact to explain behavior change to people [48]. The evangelical tool of affirmation/empowerment may be instructive, involving individuals in solving problems by emphasizing their ability to make a difference [48]. These affirmative approaches approximate seeking personal commitment, a component of the community-based social marketing toolkit. Lin notes that evangelicalism “...involves a conscious, life-encompassing choice manifested in public professions of faith. Public acts of commitment affirm new identities and bring into force the norms of a particular community" ([48], p. 1189). Although individual pledges are resource intensive to obtain, the studies highlighted earlier indicate a high degree of success where a personal commitment to behaviour change was sought.

The literature thus indicates that complementary mechanisms can improve the performance of environmental regulation by activating personal norms. A small number of case studies of specific community-based social marketing programs provide further indications of the potential gains.

\subsection{Case Studies of Community-Based Social Marketing Programs Supporting Regulation}

While the examples below are few, they illustrate the potential for community-based social marketing tools to complement regulatory strategy. In Portland, Oregon, the Department of Environment Quality implemented a successful program to achieve the U.S. Environmental Protection Agency's (EPA's) legislated air pollution standards [106]. When metropolitan Portland failed to meet the standards under the Clean Air Act, the Oregon Department of Environmental Quality in 1995 initiated the Air Quality Public Education and Incentive program, a non-regulatory plan to meet the legislative standard. The program was federally approved as part of the State Implementation Program under the Clean Air Act. It targeted activities which had an impact upon emission of volatile organic compounds (VOCs) — such as vehicle and lawnmower use, and the use of certain paints and consumer products. The program relied upon community partnerships and donations from businesses, and grants from the EPA. The budget was approximately $\$ 250,000$ per annum. The program of behavioral interventions was implemented in partnership with local businesses. It included: 
- Clean Air Action Days: When smog levels were extremely high, voluntary pollution prevention actions were recommended by participating businesses to customers and employees. These included a reduction in driving, petroleum powered lawnmower use, and aerosol use. Retailers posted signs in their stores and held in-store announcements. This extended to media advertising by retailers such as Wal-Mart and car dealerships, which promoted "car smart" ideas such as carpooling and lower emission cars. Businesses were rewarded through complimentary advertising in the Portland Business Journal.

- Non-work Trip Reduction: Portland General Electric and Blockbuster Video encouraged residents to reduce non-work trips through a pledge program asking them to seek an alternative to driving alone to the video store. Where customers did so, they were rewarded with a discount on their video rental. A car sharing program was implemented in one neighborhood.

- Sale of low-VOC consumer products: Retail store Fred Meyer promoted low-VOC emission products through shelf signage, in-store announcements, and buttons for staff that provided information about choosing products lower in VOC emissions. Promotions were held for low-VOC products, such as discounts for low-VOC paint.

- Lawnmower Buy Back Scheme: A gasoline lawnmower buy-back scheme was implemented to encourage residents to swap to electric or push mowers. Rebates were offered on electric and push mowers. The program was promoted through television advertising, in-store promotions, neighborhood events (such as a lawnmower-a-thon to test different types of lawnmowers). The program was very successful, particularly once rebates were offered on all brands of electric and push mowers.

- Paint Pollution Prevention: A partnership was formed between three paint manufacturers to promote their low and zero-VOC paint products. One manufacturer offered discount coupons on the purchase of their products. Sales of zero-VOC paint increased, and several paint manufacturers abandoned production of paints with high-VOC emissions.

The community-based social marketing initiatives implemented in this program resulted in a significant reduction in VOC emissions. Oregon was re-categorized as having attained the legislative standards set out in the Clean Air Act. This case illustrates of how a range of behavior change tools, including incentives, commitment, prompts, and effective communication of information, can enhance individual compliance with regulation.

In Kamloops, British Columbia, water restriction regulations were implemented, supported by fines for illegal watering [107]. Residents were informed that fines would commence for illegal watering. They were also informed that if they reduced demand for water, an increase in water costs would be deferred. College students conducted bicycle patrols of neighborhoods to remind residents who were illegally watering of the restrictions, and to provide conservation information. Information booths were established in shopping centers. Prompts such as refrigerator magnets with information about the restrictions were distributed. Mass media was used, including advertising about the restrictions. A 'water saving tip of the week' radio competition awarded weekly prizes and a monthly grand prize. While television advertising was not effective, the radio competition proved popular. Funds were subsequently diverted away from television advertising towards employing more bike patrol students. The community-based social marketing mechanisms supporting regulation in this case reduced water 
consumption by almost $15 \%$, with further savings on electricity costs due to the reduced demand on water pumping stations.

Kassirer et al. in a best-practices report on methods to reduce garden pesticides detail a range of community-based social marketing mechanisms used in conjunction with (and absent) regulation [108]. The combination of regulation and community-based social marketing proved potent. Only communities who passed a by-law and supported it with education or community agreements were able to significantly reduce the cosmetic use of pesticides. While the 'stick' of the law was effective, supporting this with behavior change tools was more effective [108]. In Quebec, Canada, by-laws in the communities of Hudson, St. Lazare and Notre Dame de L'Ile Perrot sought to restrict or prohibit the use of pesticides [98,109]. Prior enforcement of the by-laws had been limited. A system of escalating fines for repeat offenders was introduced, and a comprehensive community education program implemented. The education program informed residents how they could overcome pest issues without the use of pesticides - by using home visits, patrolling by inspectors, public workshops, and mass media. Warning letters were sent to those who disobeyed the law, supported by the threat of the escalating fines. Compliance with the by-laws has since been estimated around $80-90 \%$ [98,109].

Lura Consulting [108] reports on vehicle anti-idling campaigns throughout Canada. Programs which combined regulatory and voluntary approaches were the most successful, generating public support for the regulation and reducing barriers to compliance and enforcement. The Greater Toronto Area Idle Free Campaign used an idling control by-law supplemented by a multi-faceted awareness campaign that included media promotion and personal contact. Volunteer ambassadors would speak with drivers in public places (schools, gas stations) to discuss the benefits of reducing idling. They sought a commitment from drivers to change their idling behavior, promoted through the posting of a windshield decal on idle-free cars [108].

\subsection{Implementing Community-Based Social Marketing Programs to Support Regulation:} Some Observations

Regulation is frequently criticized as having too great a cost compared to its effectiveness [4]. A naïve response is simplistic deregulation. An alternative is to ask "how can we make regulation work?" There is empirical evidence that community-based social marketing mechanisms can improve understanding of and compliance with environmental law.

The literature discussed in this paper, and available case study evidence, indicates that regulatory intervention is more likely to be more cost-effective when it is embedded within a broader strategy to change behavior $[1,4,23,45,47,48,53,57,72,98,108]$. As Lin eloquently states “...efforts to change individual behavior should not rely exclusively on any single approach such as voluntary behavioral changes or strict mandates. The breadth and severity of the problem demand the deployment of a range of policy tools, including traditional forms of regulation, economic incentives, information-based regulation, education, and voluntary efforts. Numerous factors affect behavior, and the effectiveness of any particular tool for bringing about behavioral change will depend on context" ([48], p. 1148). The evidence presented in this paper shows that mechanisms to alter norms have the potential to markedly improve regulatory performance in some settings. Community based social marketing offers a well 
developed mix of supplementary interventions to support behavior change. Conversely, regulation can offer community-based social marketing mechanisms 'legal weight' and add a 'sense of seriousness' to issues that voluntary approaches alone lack [5,98,108]. The regulatory strategies detailed by Vandenbergh [53], Vandenbergh and Steinemann [45], and Dernbach [1] discussed earlier each illustrate how environmental legislation may provide a credible framework for more effective behavior change mechanisms. Synergy is available, but the praxis of combining law and community-based social marketing is undeveloped.

As Stern notes, the 'record of single-strategy approaches to changing consumer behavior is, in short, mixed at best' ([50], p. 10789). Community-based social marketing offers a range of approaches that can be tailored to the target audience $[22,57]$. Both regulatory and community-based social marketing theorists have explained that tools which focus on changing norms will prove useful, alongside effective and innovative communication strategies [57]. However, the mix and intensity of tools applied alongside regulation requires careful consideration. There will be a different 'constellation of barriers and benefits' [57] for different desired behaviors, and the barriers that prevent individuals from engaging in one type of sustainable activity (e.g., cost, time, resources) may not prevent them from adopting other sustainable behaviors [57]. Given the complexity of sustainability issues, we need far more knowledge about behavior change and regulation.

Realizing the potential of this synergy will require teamwork between legal and community-based social marketing practitioners in design and implementation. The more successful programs have involved a range of partners, including commercial, government, and voluntary organizations. Trans-disciplinary praxis is often lauded but is enormously challenging to achieve. It requires not only new combinations of instruments but also new modes of collaboration.

There are ample 'real-world' opportunities to test for the development of innovative community-based social marketing approaches to support regulation. The case studies have illustrated these for water use, emissions, energy use and energy efficiency. What is as yet lacking is a body of legal and behavioral researchers prepared to pioneer the conversion of these opportunities into practice and knowledge.

\section{Conclusions}

A common thread in the literature is that the effectiveness of regulation depends on the integration of sophisticated behavioral understanding into its design and implementation. A number of legal scholars have pointed in this direction. Martin proposes that there is a need for a behavioral jurisprudence 'in service of sustainability.' He argues that the absence of behavioral orientation from environmental law inhibits thinking about the law as a means to achieve social outcomes, thereby reducing its effectiveness [2]. Gunningham and Grabosky advocate the concept of 'smart regulation', the careful selection and use of multiple policy instruments applied intelligently, as a means of achieving successful regulatory design [18]. Martin and Verbeek [22] suggest a three-pronged approach to effective regulatory design that comprises management of total systems by understanding and managing transaction behavior, the use of multiple instruments at multiple points, and a structured evaluation of impediments and supports to desired change (see also [110]). Community-based social marketing scholarship points to specific, actionable approaches to implementing parts of these 'ideal' 
regulatory systems. This scholarship suggests that, in conjunction with environmental regulation, community-based social marketing offers the ability to better manage individual environmental behavior through a whole-systems approach of identifying and overcoming barriers to change, a comprehensive menu of behavior change tools, and ongoing feedback and evaluation.

While individual behavior may be viewed "...as "silly" - not the stuff of rigorous, rational regulatory policy", the time has come for regulators to "...treat the individual sector with the same level of sophistication and rigor as the industrial sector and other sectors" ([45], p. 1740). Further engaged scholarship will lead to a better understanding of how behaviorally effective environmental regulation can be designed and implemented. There is a need for carefully structured experiments to create a specific body of regulatory community-based social marketing knowledge. Why should legal, environmental or social change practitioners embrace both the opportunities and complexities involved in marrying community-based social marketing to regulation? The answer is 'because all of the indicators are that this can materially improve the effectiveness of sustainability strategies'. That reason alone ought to be sufficient to trigger the further development of this emerging field of research and praxis.

\section{Acknowledgements}

The Author wishes to acknowledge Jay Kassirer from Cullbridge Communications for helpful insights into the use of community-based social marketing tools; Paul Martin from the Australian Centre for Agriculture and Law for comments on a draft of this paper; John Becker, Al Luloff and James Finley from Pennsylvania State University for their insights into law and behavior; and Hannah Taylor for research assistance.

\section{References and Notes}

1. Dernbach, J.C. Harnessing individual behavior to address climate change: Options for congress. Virginia Environ. Law J. 2007, 26, 107-157.

2. Martin, P. The changing role of law in the pursuit of sustainability. In Biodiversity, Conservation, Law and Livelihoods: Bridging the North-South Divide; Jeffery, M., Firestone, J., Bubna-Litic, K., Eds.; Cambridge University Press: New York, NY, USA, 2008; pp. 49-65.

3. Designing Government: From Instruments to Governance; Eliadis, P., Hill, M., Howlett, M., Eds.; McGill-Queen's University Press: Montreal, Canada, 2004.

4. Martin, P.; Bartel, R.; Sinden, J.; Gunningham, N.; Hannam, I. Research Report: Developing a Good Regulatory Practice Model for Environmental Regulations Impacting on Farmers; Australian Farm Institute: Surry Hills, Australia, 2007.

5. May, P.J. Compliance motivations: Affirmative and negative bases. Law Society Rev. 2004, 38, 41-68.

6. May, P.J.; Winter, S. Regulatory enforcement and compliance: Examining Danish agro-environmental policy. J. Policy Analysis Manage. 1999, 13, 625-651.

7. Bentham, J. An Introduction to the Principles of Morals and Legislation; Harrison, W., Ed.; Basil Blackwell: Oxford, UK, 1789. 
8. Becker, G. Crime and punishment: An economic approach. J. Polit. Econ. 1968, 76, 169-217.

9. Tyler, T. Why People Obey the Law; Yale University Press: London, UK, 1990.

10. Sutinen, J.; Kuperan, K. A socio economic theory of regulatory compliance. J. Soc. Econ. 1999, 26, 174-193.

11. Jenny, A.; Hechavarria Fuentes, F.; Mosler, H.J. Psychological factors determining individual compliance with rules for common pool resource management: The case of a Cuban community sharing a solar energy system. Hum. Ecol. 2009, 35, 239-250.

12. Etzioni, A. The Moral Dimension; Free Press Collier Macmillan: London, UK, 1988.

13. Frank, R.H. Passions within Reason; W.W. Norton: New York, NY, USA, 1988.

14. Beyond Self-Interest; Mansbridge, J., Ed.; The University of Chicago Press: Chicago, IL, USA, 1990.

15. Thaler, R. Quasi-Rational Economics; Russell Sage Foundation: New York, NY, USA, 1991.

16. Bardach, E.; Kagan, R.A. Going by the Book: The Problem of Regulatory Unreasonablenes, 2nd ed.; Transaction Books: New Brunswick, NJ, USA, 2002.

17. Levi, M. Consent, Dissent, and Patriotism; Cambridge University Press: Cambridge, UK, 1997.

18. Gunningham, N.; Grabosky, P. Smart Regulation: Designing Environmental Policy; Oxford University Press: New York, NY, USA, 1998.

19. Gunningham, N.; Sinclair, D. Leaders and Laggards: Next Generation Environmental Regulation; Greenleaf Publishing: Sheffield, UK, 2002.

20. Ayres, I.; Braithwaite, J. Responsive Regulation: Transcending the Deregulation Debate; Oxford University Press: New York, NY, USA, 1992.

21. Young, M.D.; Gunningham, N.; Elix, J.; Lambert, J.; Howard, B.; Grabosky, P.; McCrone, E. Reimbursing the Future: An Evaluation of Motivational, Voluntary, Price-based, Property-right and Regulatory Incentives for the Conservation of Biodiversity; Biodiversity Series Paper No 9.; Biodiversity Unit, Department of the Environment, Sport and Territories: Canberra, Australia, 1996.

22. Martin, P.; Verbeek, M. Cartography for Environmental Law: Finding New Paths to Effective Resource Regulation; The Profit Foundation: Sutherland, Australia, 2000.

23. Martin, P.; Verbeek, M. Sustainability Strategy; The Federation Press: Sydney, Australia, 2006.

24. Paehlke, R. Regulatory and non-regulatory approaches to environmental protection. Can. Public Adm. 1990, 33, 17-36.

25. Feldman, I.R. Business and industry: Transitioning to sustainability. In Agenda for a Sustainable America; Dernbach, J., Ed.; Environmental Law Institute Press: Washington, DC, USA, 2009; pp. 71-91.

26. Albaredo, L.; Lozano, J.; Ysa, T. Public policies on corporate social responsibility: The role of governments in Europe. J. Bus. Ethics 2007, 74, 391-407.

27. Hartman, L.P.; Rubin, R.S.; Dhanda, K.K. The communication of corporate social responsibility: United States and European Union multinational corporations. J. Bus. Ethics 2007, 74, 373-389. 
28. Waldman, D.A.; De Luque, M.S.; Washburn, N.; House, R.J.; Adetoun, B.; Barrasa, A.; Bobina, M.; Bodur, M.; Chen, Y.J.; Debbarma, S.; Dorfman, P.; Dzuvichu, R.R.; Evcimen, I.; Pingping, F.; Grachev, M.; Duarte, R.G.; Gupta, V.; Den Hartog, D.N.; De Hoogh, A.H.B.; Howell, J. Cultural and leadership predictors of corporate social responsibility values of top management: A globe study of 15 countries. J. Int. Bus. Stud. 2006, 37, 823-837.

29. Graafland, J.; van de Ven, B. Strategic and moral motivation for corporate social responsibility. J. Corp. Citizenship 2006, 22, 111-123.

30. Laszlo, C. The Sustainable Company; Island Press: Washington, DC, USA, 2003.

31. Hitchcock, D.; Willard, M. The Business Guide to Sustainability: Practical Strategies and Tools for Organizations; Earthscan: London, UK, 2009.

32. Campbell, J.L. Why would corporations behave in socially responsible ways? An institutional theory of corporate social responsibility. Acad. Manage. Rev. 2007, 32, 946-967.

33. Bendell, J. In whose name? The accountability of corporate social responsibility. Dev. Pract. 2005, 15, 362-374.

34. Tueth, M. Fundamentals of Sustainable Business: A Guide for the Next 100 Years; World Scientific Publishing: Singapore, 2009.

35. Jayne, V. Sustainable and responsible now a fact of management life? N. Z. Manage. 2004, 51, 26-33.

36. Holliday, C.; Schmidheiny, S.; Watts, P. Walking the Talk: The Business Case for Sustainable Development; Greenleaf Publishing: Sheffield, UK, 2002.

37. Black, L.D.; Hartel, C.E.J. The five capabilities of socially responsible companies. J. Publ. Aff. 2003, 4, 125-144.

38. Esty, D.; Winston, A. Green to Gold: How Smart Companies Use Environmental Strategy to Innovate, Create Value, and Build Competitive Advantage; Yale University Press: New Haven, CT, USA, 2006.

39. Gil Estallo, M.D.A.; Finer de-la Fuente, F.; Griful-Miquela, C. The importance of corporate social responsibility and its limits. Int. Adv. Econ. Res. 2007, 13, 379-388.

40. Blowfield, M.; Frynas, J.G. Setting new agendas: Critical perspectives on corporate social responsibility in the developing world. Int. Aff. 2005, 81, 499-513.

41. Willard, B. The Next Sustainability Wave: Building Boardroom Buy-in; New Society Publishers: Gabriola Island, Canada, 2005.

42. Keijers, G. Business, Government and Sustainable Development; Routledge: Oxfordshire, UK, 2005.

43. Kotler, P.; Lee, N. Corporate Social Responsibility: Doing the Most Good for Your Company and Your Cause; John Wiley and Sons: Hoboken, NJ, USA, 2005.

44. See generally November 2005 issue of the Environmental Law Reporter 2005, 35, 10723-10799, special issue from "The Next Frontier: Individual and Household Environmental Behavior" symposium, Vanderbilt University, April 22, 2005.

45. Vandenbergh, M.P.; Steinemann, A.C. The Carbon Neutral Individual. N.Y. Univ. Law Rev. 2007, 82, 1673.

46. Vandenbergh, M.P. From smokestack to SUV: The individual as regulated entity in the new era of environmental law. Vanderbilt Law Rev. 2004, 57, 515-628. 
47. Johnson, S.M. Is religion the environment's last best hope? Targeting change in individual behavior through personal norm activation. J. Environ. Law Litigation 2009, 24, 119-164.

48. Lin, A.C. Evangelizing climate change. N. Y. Univ. Environ. Law J. 2009, 17, 1135-1193.

49. Vandenbergh, M.P. The individual as polluter. Environ. Law Rep. 2005, 35, 10723-10744.

50. Stern, P.C. Understanding individuals' environmentally significant behavior. Environ. Law Rep. 2005, 35, 10785-10790.

51. Farber, D. Controlling pollution by individuals and other dispersed sources. Environ. Law Rep. 2005, 35, 10745-10753.

52. Carlson, A.E. Recycling norms. Calif. Law Rev. 2001, 89, 1231-1300.

53. Vandenbergh, M.P. Order without social norms: How personal norm activation can protect the environment. North Western Univ. Law Rev. 2005, 99, 1101.

54. Cohen, M.A. Individual and household environmental behavior: What does economics contribute to the discussion? Environ. Law Rep. 2005, 35, 10754-10762.

55. Carlson, A.E. Social norms and individual environmental behavior. Environ. Law Rep. 2005, 35, 10763-10769.

56. Pollard, T. Driving change: Public policies, individual choices, and environmental damage. Environ. Law Rep. 2005, 35, 10791-10799.

57. McKenzie-Mohr, D.; Smith, W. Fostering Sustainable Behavior: An Introduction to Community-Based Social Marketing; New Society Publishers: Gabriola Island, BC, USA, 1999.

58. Kotler, P.; Zaltman, G. Social marketing: An approach to planned social change. J. Mark. 1971, 35, 3-12.

59. Kotler, P.; Roberto, N.; Lee, N. Social Marketing: Improving the Quality of Life; Sage Publications: Thousand Oaks, CA, USA, 2002.

60. Lefebvre, R.C.; Flora, J.A. Social marketing and public health intervention. Health Educ. $Q$. 1988, 15, 300-301.

61. Andreasen, A.R. Social marketing: Its definition and domain. J. Public Policy Market. 1994, 13, 108-114.

62. Andreasen, A.R. Marketing Social Change: Changing Behavior to Promote Health, Social Development, and the Environment; Jossey Bass: San Francisco, CA, USA, 1995.

63. Neiger, B.L.; Thackeray, R.; Barnes, M.D.; McKenzie, J.F. Positioning social marketing as a planning process for health education. Am. J. Health Stud. 2003, 18, 75-81.

64. Lindenberger, K. Publishers notes. Soc. Mar. Q. 2001, 7, 2-3.

65. Donovan, R.; Henley, N. Social Marketing: Principles and Practice; IP Communications: Melbourne, Australia, 2003.

66. Andreasen, A.R. The life trajectory of social marketing: Some implications. Market. Theory 2003, 3, 293-303.

67. Kline Weinreich, N. Hands-on Social Marketing; Sage Publications: Thousand Oaks, CA, USA, 1999.

68. Pfeiffer, J. Condom social marketing, Pentecostalism, and structural adjustment in Mozambique: A clash of aids prevention messages. Med. Anthropol. Q. 2004, 18, 77-103.

69. Larson, M.A.; Massetti-Miller, K.L. Measuring change after a public education campaign. Public Relations Rev. 1984, 10, 23-32. 
70. Costanzo, M.; Archer, D.; Aronson, E.; Pettigrew, T. Energy conservation behavior: The difficult path from information to action. Am. Psychol. 1986, 41, 521-528.

71. Johnston, C.E. Developing sustainable behaviors through community-based social marketing. In Examining the Confluence of Environmental and Water Concerns: Proceedings of the World Environmental and Water Resources Congress 2006, Omaha, NE, USA, 21-25 May 2006; Graham, R., Ed.; American Society of Civil Engineers: Reston, VA, USA, 2006.

72. Kollmuss, A.; Agyeman, J. Mind the gap: Why do people act environmentally and what are the barriers to pro-environmental behavior? Environ. Educ. Res. 2002, 8, 239-260.

73. Cialdini, R.B. Influence: Science and Practice; HarperCollins: New York, NY, USA, 1993.

74. Pallak, M.S.; Cook, D.A.; Sullivan, J.J. Commitment and energy conservation. In Applied Social Psychology Annual; Bickman, L., Ed.; Sage: Beverley Hills, CA, USA, 1980; pp. 235-253.

75. Fostering Sustainable Behavior: Community-based Social Marketing. Using Commitment to Reduce Energy Consumption in Iowa City; Available online: http://www.cbsm.com/cases/using +commitment+to+reduce+energy+consumption+in+iowa+city_85/(accessed on 2 October 2009).

76. Tools of Change. Iowa City; Available online: http://www.toolsofchange.com/English/Case Studies/default.asp?ID=14 (accessed on 2 October 2009).

77. Winett, R.A.; Hatcher, J.W.; Fort, T.R.; Leckliter, I.N.; Love, S.Q.; Riley, A.W.; Fishback, J.F. The effects of videotape modeling and daily feedback on residential electricity conservation, home temperature and humidity, perceived comfort, and clothing worn: Winter and summer. J. Appl. Behav. Anal. 1982, 15, 381-402.

78. Winnett, R.A.; Leckliter, I.N.; Chinn, D.E.; Stahl, B.; Love, S.Q. Effects of television modeling on residential energy conservation. J. Appl. Behav. Anal. 1985, 18, 33-44.

79. Aronson, E. Applying social psychology to desegregation and energy conservation. Pers. Soc. Psychol. Bull. 1990, 16, 118-132.

80. Fostering Sustainable Behavior: Community-Based Social Marketing. Improving Energy Conservation with Effective Home Audit Programs in California Using Communication and Commitment; Available online: http://www.cbsm.com/cases/improving+energy+conservation +with+effective+home+audit+programs+in+California+using+communication+and+commitmen t_90 (accessed on 5 October 2009).

81. Tools of Change. Pacific Gas and Electric; Available online: http://www.toolsofchange.com/ English/CaseStudies/default.asp?ID=17 (accessed on 3 October 2009).

82. Gardner, G.T.; Stern, P.C. Environmental Problems and Human Behavior; Allyn and Bacon: Boston, MA, USA, 1996.

83. Wang, T.H.; Katzev, R.D. Group commitment and resource conservation: Two field experiments on promoting recycling. J. Appl. Soc. Psychol. 1990, 20, 265-275.

84. Fostering Sustainable Behavior: Community-Based Social Marketing. Increasing Paper Recycling in Portland Oregon Dormitories Using Incentives and Commitment; Available online: http://www.cbsm.com/cases/increasing+paper+recycling+in+portland+oregon+dormitories+usin g+incentives+and+commitment_105 (accessed on 4 October 2009).

85. Austin, J.; Hatfield, D.B.; Grindle, A.C.; Bailey, J.S. Increasing recycling in office environments: The effects of specific, informative cues. J. Appl. Behav. Anal. 1993, 26, 247-253. 
86. Fostering Sustainable Behavior: Community-Based Social Marketing. The Use of Prompts in Increasing Recycling in Academic University Departments; Available online: $\mathrm{http}: / / \mathrm{www} . c b s m . c o m / c a s e s /$ the+use+of+prompts+in+increasing+recycling+in+academic+univer sity+departments_114 (accessed on 5 October 2009).

87. Schultz P.W.; Nolan, J.M.; Cialdini, R.B.; Goldstein, N.J.; Griskevicius, V. The constructive, destructive, and reconstructive power of social norms. Psychol. Sci. 2007, 18, 429-434.

88. Borsari, B.; Carey, K. Descriptive and injunctive norms in college drinking: A meta-analytic integration. J. Stud. Alcohol. 2003, 64, 331-341.

89. Prentice, D.A.; Miller, D.T. Pluralistic ignorance and alcohol use on campus: Some consequences of misperceiving the social norm. J. Pers. Soc. Psychol. 1993, 64, 243-256.

90. Clapp, J.D.; McDonnell, A. The relationship of perceptions of alcohol promotion and peer drinking norms to alcohol problems reported by college students. J. Coll. Stud. Dev. 2000, 41, 19-26.

91. Fostering Sustainable Behavior: Community-Based Social Marketing. Using Social Norms to Reduce Household Energy Consumption; Available online: http://www.cbsm.com/cases/using+ social+norms+to+reduce+household+energy+consumption_170 (accessed on 2 October 2009).

92. Sunstein, C.R. Social norms and social roles. Columbia Law Rev. 1996, 96, 903.

93. Geller, E.S. Prevention of environmental problems. In Handbook of Prevention; Edelstein, B.A., Michelson, L., Eds.; Plenum: New York, NY, USA, 1986; pp. 361-383.

94. DeYoung, R. Changing behavior and making it stick: The conceptualization and management of conservation behavior. Environ. Behav. 1993, 25, 485-505.

95. DeYoung, R. Encouraging environmentally appropriate behavior: The role of intrinsic motivation. J. Environ. Syst. 1986, 15, 281-291.

96. DeYoung, R. Some psychological aspects of reduced consumption behavior: The role of intrinsic satisfaction and competence motivation. Environ. Behav. 1996, 28, 358-409.

97. Vining, J.; Ebreo, A. Emerging theoretical and methodological perspectives on conservation behavior. In New Handbook of Environmental Psychology; Bechtel, R., Churchman, A., Eds.; Wiley: New York, NY, USA, 2002; pp. 541-558.

98. Kassirer, J.; Kowsan, S.; Spence, K.; Morphet, S.; Wolnik, C.; Goom, S.; Del Matto, T. Impact of By-Laws and Public Education Programs on Reducing the Cosmetic/Non-Essential, Residential Use of Pesticides: A Best Practices Review; The Canadian Centre for Pollution Prevention and CULLBRIDGETM Marketing and Communications: Ottawa, Canada, 2004.

99. Hetcher, S. Norms as limited resources. Environ. Law Rep. 2005, 35, 10770-10784.

100. Stern, P.C.; Dietz, T.; Abel, T.; Guagnano, G.A.; Kalof, L. A value-belief-norm theory of support for social movements: The case of environmentalism. Hum. Ecol. Rev. 1999, 6, 81-97.

101. McAdams, R.H. The Origin, Development, and Regulation of Norms. Mich. Law Rev. 1997, 96, 338.

102. Posner, R. Social norms, social meaning, and economic analysis of law: A comment. J. Legal Stud. 1998, 27, 553.

103. Ellickson, R.C. Law and economics discovers social norms. J. Legal Stud. 1998, 27, 537.

104. Lessig, L. The new Chicago school. J. Legal Stud. 1998, 27, 661. 
105. Ellickson, R.C. Order without Law: How Neighbors Settle Disputes; Harvard University Press: Cambridge, MA, USA, 1991.

106. Tools of Change. Oregon's Air Quality and Public Education Program; Available online: http://www.toolsofchange.com/en/case-studies/detail/101/ (accessed on 1 October 2009).

107. Tools of Change. Water Smart; Available online: http://www.toolsofchange.com/en/casestudies/detail/23/ (accessed on 1 October 2009).

108. Lura Consulting. The Carrot, the Stick, and the Combo: A Recipe for Reducing Vehicle Idling in Canadian Communities, 2005; Report prepared for Natural Resources Canada Clean Air Partnership; Available online: http://oee.nrcan.gc.ca/communities-government/transportation/ municipal-communities/reports/carrot-stick-combo/carrot-stick-combo.pdf (accessed on 28 September 2009).

109. Tools of Change. Reducing Pesticide Use in Hudson, St. Lazare, and Notre Dame de L'Ile Perrot; Available online: http://www.toolsofchange.com/en/case-studies/detail/172/ (accessed on 1 October 2009).

110. Martin, P.; Williams, J.; Stone, C. Transaction Costs and Water Reform: The Devils Hiding in the Details; Cooperative Research Centre for Irrigation Futures Technical Report No. 08/08; Available online: http://www.irrigationfutures.org.au/news.asp?catID=9\&ID=768 (accessed on 28 October 2009).

(C) 2010 by the author; licensee MDPI, Basel, Switzerland. This article is an open-access article distributed under the terms and conditions of the Creative Commons Attribution license (http://creativecommons.org/licenses/by/3.0/). 